\title{
Markedly Ring-enhanced Optic Nerves Due to Metastasis of Signet-ring Cell Gastric Carcinoma
}

\author{
Yuichi Hayashi, Takehiro Kato, Yuji Tanaka, Megumi Yamada, Akihiro Koumura, \\ Akio Kimura, Isao Hozumi and Takashi Inuzuka
}

Key words: MRI, signet-ring cell carcinoma, optic nerve, cerebrospinal fluid, optic neuropathy, leptomeningeal carcinomatosis

(Inter Med 49: 517, 2010)

(DOI: 10.2169/internalmedicine.49.3081)

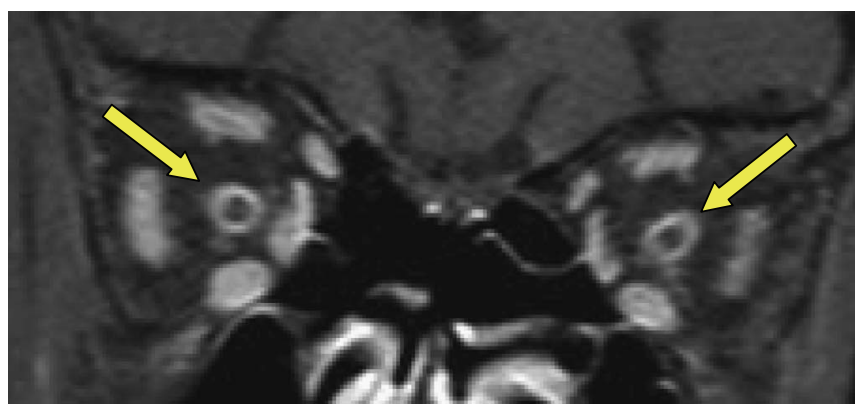

Picture 1. Coronal fat-suppressed MRI with gadolinium showed a marked ring enhancement of the surrounding optic nerves (arrows).
Signet-ring cell carcinoma frequently causes leptomeningeal carcinomatosis, one cause of optic neuropathy in elderly patients. A 77-year-old woman had shown progressive bilateral blindness for one month without any other symptoms. Coronal fat-suppressed MRI with gadolinium showed a marked ring enhancement of the surrounding optic nerves (Picture 1). CSF cytodiagnosis and histopathological examination of the gastric biopsy samples revealed signetring cell carcinoma. The patient was diagnosed with leptomeningeal carcinomatosis due to gastric cancer. She died 2 weeks after the diagnosis. Coronal fat-suppressed MRI with gadolinium is useful for the differential diagnosis of optic neuropathy, especially leptomeningeal carcinomatosis $(1,2)$.

\section{References}

1. Sung JU, Lam BL, Curtin VT, Tse DT. Metastatic gastric carcinoma to the optic nerve. Arch Ophthalmol 116: 692-693, 1998.

2. Suto C, Oohira A, Funaki C, Kanno S, Mori Y. Pathological find- ings of optic neuropathy from metastatic leptomeningeal carcinomatosis. Jpn J Ophthalmol 51: 396-398, 2007.

Department of Neurology and Geriatrics, Gifu University Graduate School of Medicine, Gifu

Received for publication October 29, 2009; Accepted for publication November 17, 2009

Correspondence to Dr. Yuichi Hayashi, hayashiy@gifu-u.ac.jp

(C) 2010 The Japanese Society of Internal Medicine Journal Website: http://www.naika.or.jp/imindex.html 